\title{
Evaluating the delivery, impact, costs and benefits of an active lives programme for older people living in the community
}

\author{
Rob Gandy ${ }^{1,2}$, Amelia Bell ${ }^{3}$, Bob McClelland ${ }^{4}$ and Brenda Roe ${ }^{5,6}$ \\ ${ }^{1}$ Visiting Professor, Liverpool Business School, Liverpool John Moores University, Liverpool, UK \\ ${ }^{2}$ Honorary Senior Lecturer, Care Profiles Development Programme, Edge Hill University, Ormskirk, UK \\ ${ }^{3}$ Senior Lecturer Adult Nursing, Faculty of Health and Social Care, Edge Hill University, Ormskirk, UK \\ ${ }^{4}$ Reader in Educational Technology, Research Forum Chair, Liverpool Business School, Liverpool John Moores \\ University, Liverpool, UK \\ ${ }^{5}$ Professor of Health Research, Evidence-Based Practice Research Centre, Faculty of Health \& Social Care, \\ Edge Hill University, Ormskirk, UK \\ ${ }^{6}$ Honorary Fellow, Personal Social Services Research Unit (PSSRU), University of Manchester, Manchester, UK
}

\begin{abstract}
Aim: Age UK Lancashire received Big Lottery funding to deliver an active lives programme from January 2012 to December 2014 to the population of West Lancashire aged over 50 years. The overall aims of the associated evaluation were to measure older people's experiences of participating in the programme, identify the impacts on their health and well-being and their suggestions for services development, and establish the costs and benefits of the programme. Background: The World Health Organisation recommends older people should be able to achieve physical, social and mental well-being throughout their lives, and that international, national and local policies should be developed to support older adults, promote their independence and well-being, and encourage physical exercise. Consequently, the West Lancashire programme was to establish preventative community support for older people to assist in improving their well-being and physical and mental health, particularly those isolated due to age-related illness or disability. It was to provide interventions not available from local social care providers. Methods: A mixed methods approach was adopted, with the qualitative evaluation utilising focus groups to establish people's experiences, identify impacts on their health and well-being, and suggestions for services development. This paper describes the quantitative evaluation, which involved three surveys and a costs analysis. The surveys were scheduled to give timely feedback to management about programme delivery and content, and overall benefits of participation. Findings: The active lives programme and groups offered a wide range of flexible and local activities that provided benefits for older people in terms of health and well-being, social well-being and quality of life, and reducing social isolation. There was interconnectivity between these benefits. The programme was delivered in an affordable and flexible manner. Such programmes should be made more widely available.
\end{abstract}

Key words: active ageing; costs analysis; older people; quality of life; social isolation

Received 25 November 2015; revised 4 July 2016; accepted 8 July 2016; first published online 19 August 2016

Correspondence to: Rob Gandy, Visiting Professor, Liverpool Business School, Liverpool John Moores University, Redmonds Building, Brownlow Hill, Liverpool, Merseyside L3 5UG, UK. Email: rob.gandy@ntlworld.com

\section{Introduction}

The needs of ageing populations should be positively addressed, with the challenge to ensure quality of life with increasing age (Brown et al., 2004)

(C) Cambridge University Press 2016 
despite greater prevalence of long-term conditions and their health consequences (Stern and Konno, 2009). The World Health Organisation (WHO) (2015) recommended older people should be able to achieve physical, social and mental well-being throughout their lives, and defined active ageing as 'the process of optimising opportunities for health, participation and security in order to enhance quality of life as people age' (WHO, 2002: 12). It also recommended the development of international, national and local policies to support older adults, promote their independence and well-being, and encourage physical exercise (WHO, 2012).

The Big Lottery (2015) provided Age UK Lancashire (AUKL), in the North West of England, with c. $£ 96000$ annual funding to deliver an active lives programme from January 2012 to December 2014. The aim was to establish (secondary) preventative community support for older people to assist in improving their well-being and physical and mental health, and prevent worsening of established problems. It was to benefit people aged over 50 years across West Lancashire, particularly those isolated due to age-related illness or disability, and provided interventions (activities groups) not available from local social care providers. Although not specifically targeting hard-to-reach groups (Health and Safety Executive, 2004), the programme was relevant to such communities in rural areas outside the main towns of Ormskirk and Skelmersdale.

A formal evaluation was required of the programme. This focussed on service user experiences, and adopted a mixed methods approach. The qualitative evaluation primarily utilised focus groups to establish participants' experiences, identifying the impacts on their health and well-being and suggestions for services development. The quantitative evaluation involved three surveys, scheduled to give timely feedback to management about programme delivery and content, and overall benefits of participation. Simple analyses of the costs and benefits of the overall programme were also undertaken. This paper reports the surveys and this evaluation. The qualitative evaluation findings are reported elsewhere (Bell et al., 2014).

\section{AUKL}

Age UK (2015) is the country's largest charity dedicated to helping everyone make the most of later life. AUKL is one its largest constituent organisations and has two main activity centres, in Ormskirk and Skelmersdale, with many additional events organised across the area in various local facilities.

\section{Methods}

\section{Aims and design}

The overall evaluation aims were to measure older people's experiences of participating in the active lives programme, identify the impacts on their health and well-being and their suggestions for services development. The quantitative surveys were structured to describe people's experiences at key stages of programme delivery, with the results providing contemporary feedback to AUKL on whether: the programme was set up and organised properly; groupings of site, age and activity differed in areas such as agreement, satisfaction and improvement; there existed co-relationships between agreements, satisfactions and improvements; the programme was delivered appropriately; and outcomes. An associated aim was to establish the costs and benefits, to inform whether the programme and activities groups were sustainable.

There were three phases of data collection: Phase 1 - September to December 2012; Phase 2 - June to August 2013; and Phase 3 - April to June 2014. These comprised nine months, 18 months and 28 months, respectively, from the programme's commencement.

Convenience samples for each of the surveys were recruited from AUKL service users attending activities groups in Ormskirk, Skelmersdale and all other centres (the latter collectively referred to as 'Rural'). The numbers attending each activity and site reflected the nature of the activity and the physical constraints of the site. Not all groups operated every week (some were monthly). Therefore, it was decided to survey as many individual sessions as possible within each survey period. The range of activities was wide, and comprised five collective groups as follows: 'Education/Informative', 'IT/Communications', 'Physical/Exercise', 'Social Engagement' and 'Support Group'. Table 1 shows the (approximate) number of weekly sessions at each site, with examples of activities. The profiles gender, site, activity and age group were common to each survey.

\section{Ethical considerations}

Ethics approval was obtained from Edge Hill University's Faculty of Health and Social Care 
Table 1 Distribution of activities across sites by category with approximate weekly sessions

\begin{tabular}{|c|c|c|c|c|c|c|}
\hline Activity category & Ormskirk & Examples & Rural & Examples & Skelmersdale & Examples \\
\hline Education/Informative & 2.7 & $\begin{array}{l}\text { Arts and crafts } \\
\text { group; Spanish/ } \\
\text { French class }\end{array}$ & 0.5 & $\begin{array}{l}\text { Help direct; food } \\
\text { hygiene }\end{array}$ & 0.8 & $\begin{array}{l}\text { Baking class; craft } \\
\text { class }\end{array}$ \\
\hline IT/Communications & 1.3 & Computer class & 0.5 & Laptop one-to-one & 0.6 & Mobile telephone use \\
\hline Physical/Exercise & 4.0 & $\begin{array}{l}\text { Line dancing; tai chi; } \\
\text { indoor bowls; yoga }\end{array}$ & 0.6 & $\begin{array}{l}\text { Chair-based keep } \\
\text { fit }\end{array}$ & 3.0 & $\begin{array}{l}\text { Line dancing; keep } \\
\text { fit; health walks }\end{array}$ \\
\hline Social Engagement & 2.5 & $\begin{array}{l}\text { Lunch club; bridge } \\
\text { club; coffee } \\
\text { morning }\end{array}$ & 1.3 & $\begin{array}{l}\text { Lunch club; games } \\
\text { club; coffee } \\
\text { morning }\end{array}$ & 3.0 & $\begin{array}{l}\text { Senior citizens } \\
\text { group; lunch club; } \\
\text { games club }\end{array}$ \\
\hline \multirow[t]{2}{*}{ Support Group } & 2.0 & $\begin{array}{l}\text { Alzheimer's; } \\
\text { footcare surgery; } \\
\text { day care }\end{array}$ & 1.0 & Volunteer support & 0.8 & Talk diabetes \\
\hline & 12.5 & & 3.8 & & 8.2 & \\
\hline
\end{tabular}

The decimal places reflect that some activities did not have sessions every week. For example, a session every two weeks is recorded as 0.5 .

Research Ethics Committee, with the University code of conduct for undertaking research adhered to. Potential participants were given a project summary and information sheet by a person independent of the research team and those wishing to participate were advised of the date, time and venue of the surveys. Written informed consent was obtained following an overview of the study at the time of data collection. Confidentiality and anonymity were assured and participants made aware of their right to withdraw from the study at any point.

\section{Survey data collection}

Three surveys were undertaken, one for each phase, designed to cover each site and activity. A range of data collection methods were considered. AUKL determined the most practical was printing paper copies of the survey forms, and handing them to participants at the end of the sessions. Participants completed the forms manually and returned them to the session co-ordinator. AUKL used its own staff and equipment to manually input data via the internet to the central database.

The focus of each survey differed: Phase 1 focussed on the facilities used (to gauge any necessary changes in programme delivery); Phase 2 focussed on the activities themselves; and Phase 3 focussed on the impact on participants of attending activities. A small number of questions were repeated in the different surveys (see Table 3 ), with simple comparisons made between the respective responses to identify any pattern changes. In general, five-point
Likert scales were utilised for responses (for 'Agreement' $1=$ strongly disagree to $5=$ strongly agree; for 'Satisfaction' $1=$ very dissatisfied to $5=$ very satisfied; and for 'Improvement' $1=$ greatly worsened to $5=$ greatly improved), with presented responses consistent with the question wording. An option was always provided for participants to decline to answer (such responses were excluded from analysis).

\section{Analytical considerations}

Following data input and validation, data for each phase were analysed using standard descriptive methods, multiple correspondence analysis (MCA), mean difference tests and correlations. Given the number of responses for any individual activity/site combination was small, the main analyses were set at a high level, that is, for whole activity groups and individual sites, where analyses were valid.

MCA is a data analysis technique for nominal categorical data, used to detect and represent underlying structures in data sets; it can be thought of as a means of analysing all two-way cross-tabulations amongst variables (Sourial et al., 2010). Profiles which cluster within the same quadrant are those that correspond; if a profile straddles two quadrants it is classed as clustering into both. MCAs enable observations for discussion concerning the relationships among demographic profiles and the characteristics of age group, activities and sites, attendance preferences and recommendation choices. 
The benefits of attending the programme activities were inferred from the responses to specific questions that related to people's health and wellbeing, social well-being and quality of life, social isolation, and healthy eating.

Given the diversity of activity groups in terms of their nature, frequency, size and staffing, and the sites and venues involved, the costs analysis could only be performed at programme level. This used simple statistical indicators relating to 'overall average cost per session', 'overall average cost per person' and 'overall average cost per attendance'. The costs invested combined the Big Lottery grant, service user charges and any other monies AUKL could input from other fundraising. These are not necessarily the same as costs incurred, that is, actual costs, but the two were considered similar given the nature of the organisation. Because of limitations in the available financial data, the cost of the programme was deemed the same as the external funding from the Big Lottery.

\section{Reliability and validity}

The surveys' design was deliberately simple and user-friendly in order to maximise the reliability and validity. Each involved no more than seven questions with tick-boxes for indicating the chosen answer. The spaces between tick-boxes were sufficiently large to avoid incorrect marking. As survey data were anonymous responses could be open and honest and therefore valid.

A pilot study before Phase 1 tested the feasibility of recruitment and data collection from a user and analytical perspective. This involved the initially agreed Phase 1 survey forms having dummy data recorded and input by a mix of AUKL and evaluation team staff, to ensure the design and wording of instructions and questions were suitable. Feedback informed any essential modifications, which were minimal. The submitted data and database were investigated to ensure no problems with input and transmission, and that the database could be readily interrogated to produce the required analyses. No problems were identified.

All data for each phase were checked for answers/values outside those prescribed. None were detected. The database was maintained on a secure site and password protected, assuring data integrity.

Using anticipated activity levels, projections were made of the number of responses required for surveys to be deemed satisfactory. The range arrived at was 75-180. In addition, how many survey forms handed out was recorded, to compare with the number completed and returned.

Cronbach's $\alpha$ was used to measure reliability on the three surveys. The values observed for Phases 1,2 and 3 were $0.702,0.707$ and 0.634 , respectively. In this research, the reliability result exhibits a high degree of internal consistency with each standardized item $\alpha$ of $>0.60$. The Cronbach's $\alpha$ range from 0.60 to 0.99 for the variables in the questionnaires used for the study implies the instrument is reliable. Flynn et al. (1994) argued that a Cronbach's $\alpha$ of 0.60 and above was considered an effective reliability for judging a scale.

Overall activity data were requested from AUKL for a full year, primarily for the purposes of the costs analysis. This was sourced from its main information system, which it uses for its own management data and analysis, and was accepted as being appropriate and valid.

\section{Results}

Table 2 provides summary activity for the activities groups and sites for the most recent full year's activity (2013); the programme delivered 1173 sessions, involving 592 registered individuals and a total of 40634 attendances. There are clear variations between activity categories and sites, for example, the average number of attendances per session for Education/Informative was 5.9 at Ormskirk, 22.0 at Rural and 45.0 at Skelmersdale. There were similar variations between sites for the number of attendances per person. These variations reflect local priorities, the nature of the activities and the capacities of facilities.

\section{Quantitative surveys}

The response rates for Phases 1, 2 and 3 were $48 \%$ (158), 63\% (166) and 58\% (205), respectively; all within the projected sample range of 75180 participants, and acceptable for analysis. The total numbers of responses from Ormskirk, Rural and Skelmersdale in Phase 1 were 98, 33 and 27, respectively; with corresponding figures of 89,48 and 29 for Phase 2, and 74, 66 and 86 for Phase 3.

The proportion of younger participants reduced over the surveys: those aged under 65 years reduced 
Table 2 Summary of annual activity for active lives groups according to category and site

\begin{tabular}{|c|c|c|c|c|c|c|}
\hline Site & Activity & $\begin{array}{l}\text { Number of } \\
\text { sessions } \\
\text { held }\end{array}$ & $\begin{array}{l}\text { Number of } \\
\text { individuals } \\
\text { (on register) }\end{array}$ & $\begin{array}{l}\text { Total } \\
\text { number of } \\
\text { attendances }\end{array}$ & $\begin{array}{l}\text { Average } \\
\text { attendances } \\
\text { per session }\end{array}$ & $\begin{array}{l}\text { Average } \\
\text { attendances } \\
\text { per person }\end{array}$ \\
\hline Ormskirk & Education/Informative & 128 & 37 & 752 & 5.9 & 20.3 \\
\hline Ormskirk & IT/Communications & 62 & 18 & 682 & 11.0 & 37.9 \\
\hline Ormskirk & Physical/Exercise & 192 & 49 & 14544 & 75.8 & 296.8 \\
\hline Ormskirk & Social Engagement & 120 & 116 & 7056 & 58.8 & 60.8 \\
\hline Ormskirk & Support Group & 96 & 27 & 816 & 8.5 & 30.2 \\
\hline Ormskirk & Sub-total & 598 & 247 & 23850 & 39.9 & 96.6 \\
\hline Rural & Education/Informative & 24 & 27 & 528 & 22.0 & 19.6 \\
\hline Rural & IT/Communications & 22 & 18 & 242 & 11.0 & 13.4 \\
\hline Rural & Physical/Exercise & 28 & 21 & 504 & 18.0 & 24.0 \\
\hline Rural & Social Engagement & 60 & 40 & 624 & 10.4 & 15.6 \\
\hline Rural & Support Group & 48 & 22 & 864 & 18.0 & 39.3 \\
\hline Rural & Sub-total & 182 & 128 & 2762 & 15.2 & 21.6 \\
\hline Skelmersdale & Education/Informative & 36 & 53 & 1620 & 45.0 & 30.6 \\
\hline Skelmersdale & IT/Communications & 31 & 10 & 248 & 8.0 & 24.8 \\
\hline Skelmersdale & Physical/Exercise & 144 & 46 & 2928 & 20.3 & 63.7 \\
\hline Skelmersdale & Social Engagement & 144 & 70 & 8352 & 58.0 & 119.3 \\
\hline Skelmersdale & Support Group & 38 & 38 & 874 & 23.0 & 23.0 \\
\hline Skelmersdale & Sub-total & 393 & 217 & 14022 & 35.7 & 64.6 \\
\hline All centres & Education/Informative & 188 & 117 & 2900 & 15.4 & 24.8 \\
\hline All centres & IT/Communications & 115 & 46 & 1172 & 10.2 & 25.5 \\
\hline All centres & Physical/Exercise & 364 & 116 & 17976 & 49.4 & 155.0 \\
\hline All centres & Social Engagement & 324 & 226 & 16032 & 49.5 & 70.9 \\
\hline \multirow{2}{*}{ All centres } & Support Group & 182 & 87 & 2554 & 14.0 & 29.4 \\
\hline & Total & 1173 & 592 & 40634 & 34.6 & 68.6 \\
\hline
\end{tabular}

from $20 \%$ in Phase 1 to $12 \%$ in Phase 2 to $9 \%$ in Phase 3, and those aged 65-74 years similarly reduced from 36 to 33 to $26 \%$. By contrast, the proportion of participants aged 75-84 years increased from 20 to 30 to $42 \%$, and the proportion aged 85 years and over increased from 10 to 11 to $14 \%$.

The number of women in each phase was 121 $(77 \%), 140(84 \%)$ and $160(78 \%)$, respectively. Examination of the balance in responses between the activity groups over time was constrained by some non-responses (see the 'Limitations' section). However, for the full response Phase 3, Education/Informative accounted for 32\%, Support Group accounted for $20 \%$, with Physical/ Exercise, IT/Communications and Social Engagement accounting for 15,16 and $17 \%$, respectively. Noticeably, activities attendance varied for gender: in Phase 3 men accounted for $36 \%$ of IT/ Communications, $26 \%$ of Social Engagement, $23 \%$ of Education/Informative, $14 \%$ of Support Group and $10 \%$ of Physical/Exercise.

Table 3 sets out the number of responses for each question and highlights the mean scores and standard deviations. All means for variables measured were positive (greater than neutral) indicating positive agreement, satisfaction and improvement for all respective variables. For Phase 1 the highest mean agreement was 4.38 for Question E, whereas the lowest mean agreement was 4.11 for Question A (all 'agree to strongly agree'). The highest mean satisfaction was 4.37 for Question $G$, whereas the lowest mean satisfaction was 4.21 for Question F (both 'satisfied to very satisfied').

For Phase 2 the highest mean agreement was 4.47 for Question K, whereas the lowest mean agreement was 4.12 for Question I (all 'agree to strongly agree'). Phase 2 also established that 92 (56\%) respondents attended every session, 63 (38\%) attended frequently, seven (4\%) attended occasionally and two (1\%) attended rarely. In total, $162(99 \%)$ respondents said they would recommend the activity group to family and friends, with only one saying they would not.

For Phase 3 the highest mean agreement was 4.03 (agree to strongly agree) for Question N, whereas the lowest mean agreement was 3.65 (neutral to agree) for Question O. A mean 
Table 3 Descriptives (sample sizes, score means and SD for measures)

\begin{tabular}{|c|c|c|c|c|c|}
\hline Phases & & lestions & $\begin{array}{l}\text { Sample } \\
\text { size }(n)\end{array}$ & Mean & SD \\
\hline \multirow[t]{7}{*}{ Phase 1} & A & How much would you agree that the venue is easy to travel to? & 158 & 4.11 & 0.81 \\
\hline & $\mathrm{B}$ & How much would you agree that the programme activities are affordable? & 158 & 4.16 & 0.69 \\
\hline & $\mathrm{C}$ & How much would you agree that the activity programme is well organised? & 158 & 4.14 & 0.74 \\
\hline & $\mathrm{D}$ & $\begin{array}{l}\text { How much would you agree that the facilities used are appropriate for their } \\
\text { purposes? }\end{array}$ & 157 & 4.17 & 0.64 \\
\hline & $\mathrm{E}$ & How much would you agree that the toilets are satisfactory and clean? & 158 & 4.38 & 0.79 \\
\hline & $\mathrm{F}$ & How satisfied are you with the range of activities provided? & 156 & 4.21 & 0.86 \\
\hline & G & How satisfied are you with the refreshments available? & 157 & 4.37 & 0.68 \\
\hline \multirow[t]{5}{*}{ Phase 2} & I & How much would you agree that the activity programme is well organised? & 164 & 4.12 & 0.56 \\
\hline & $\mathrm{J}$ & $\begin{array}{l}\text { How much would you agree that the facilities used are appropriate for their } \\
\text { purposes? }\end{array}$ & 166 & 4.28 & 0.55 \\
\hline & $\mathrm{K}$ & $\begin{array}{l}\text { How much would you agree that you got enjoyment from the activity } \\
\text { programme? }\end{array}$ & 163 & 4.47 & 0.59 \\
\hline & $\mathrm{L}$ & $\begin{array}{l}\text { How much would you agree that the activity programme has helped your health } \\
\text { and well-being? }\end{array}$ & 163 & 4.21 & 0.69 \\
\hline & M & $\begin{array}{l}\text { How much would you agree that the activity programme has helped your social } \\
\text { well-being and quality of life? }\end{array}$ & 164 & 4.37 & 0.58 \\
\hline \multirow[t]{5}{*}{ Phase 3} & $\mathrm{~N}$ & $\begin{array}{l}\text { How much would you agree that you are less isolated socially since you started } \\
\text { attending the groups? }\end{array}$ & 193 & 4.03 & 0.81 \\
\hline & $\mathrm{O}$ & $\begin{array}{l}\text { How much would you agree that you have been eating (more) healthily since you } \\
\text { started attending the groups? }\end{array}$ & 189 & 3.65 & 0.83 \\
\hline & $\mathrm{P}$ & How satisfied have you been with the range of activities provided? & 192 & 4.02 & 0.99 \\
\hline & $\mathrm{Q}$ & $\begin{array}{l}\text { How much has your health and well-being changed through attending the } \\
\text { groups? }\end{array}$ & 193 & 3.78 & 0.74 \\
\hline & $\mathrm{R}$ & $\begin{array}{l}\text { How much has your social well-being and quality of life changed through } \\
\text { attending the groups? }\end{array}$ & 196 & 4.07 & 0.68 \\
\hline
\end{tabular}

satisfaction of 4.02 (satisfied to very satisfied) for Question $\mathrm{P}$ was observed and highest mean improvement of 4.07 (improved to greatly improved) was observed for Question R, whereas the lowest mean improvement was 3.78 (neutral to improved) for Question Q. Phase 3 established that $92(48 \%)$ respondents attended one or two groups, $70(37 \%)$ attended three or four, $17(9 \%)$ attended five or six, three $(2 \%)$ attended seven or eight and eight (4\%) attended nine or more; with a mean of 3.0. Moreover, 176 (94\%) respondents were able to attend all the activity groups that they wanted to, with only $12(6 \%)$ unable.

For each phase, a MCA was undertaken to segment the profiles into quadrants, with the results for Phases 1-3 shown in Figures 1-3, respectively. Each included the profiles Activity, Age group and Site; with 'Would you recommend to family \& friends?' included for Phase 2 and 'Have you attended all groups you wanted to?' included for Phase 3. As MCA is concerned with relationships amongst (or within) sets of variables, each MCA (as shown in the Figures) indicates

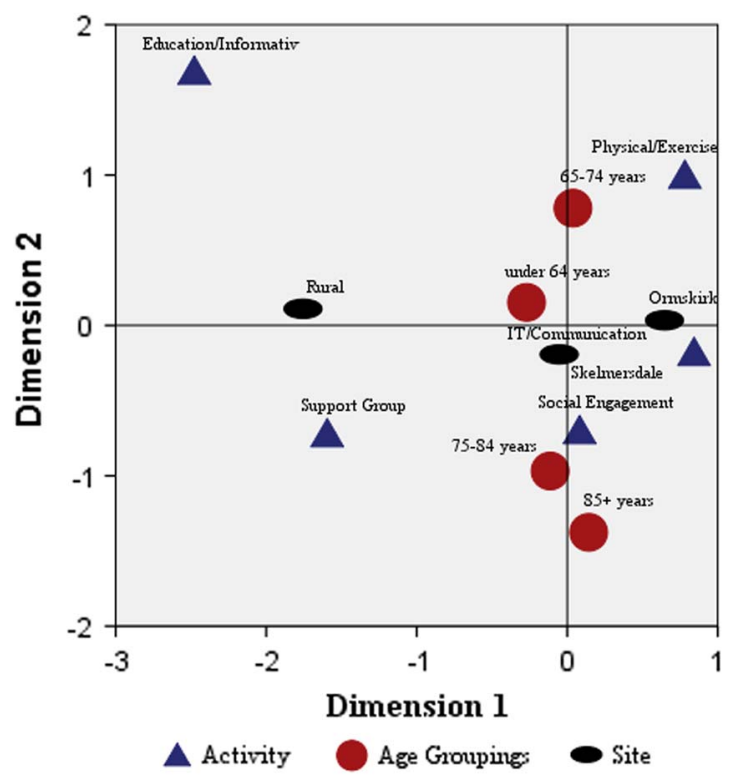

Figure 1 Segmentation of survey profiles - Phase 1

Primary Health Care Research \& Development 2017; 18: 122-134 




Figure 2 Segmentation of survey profiles - Phase 2

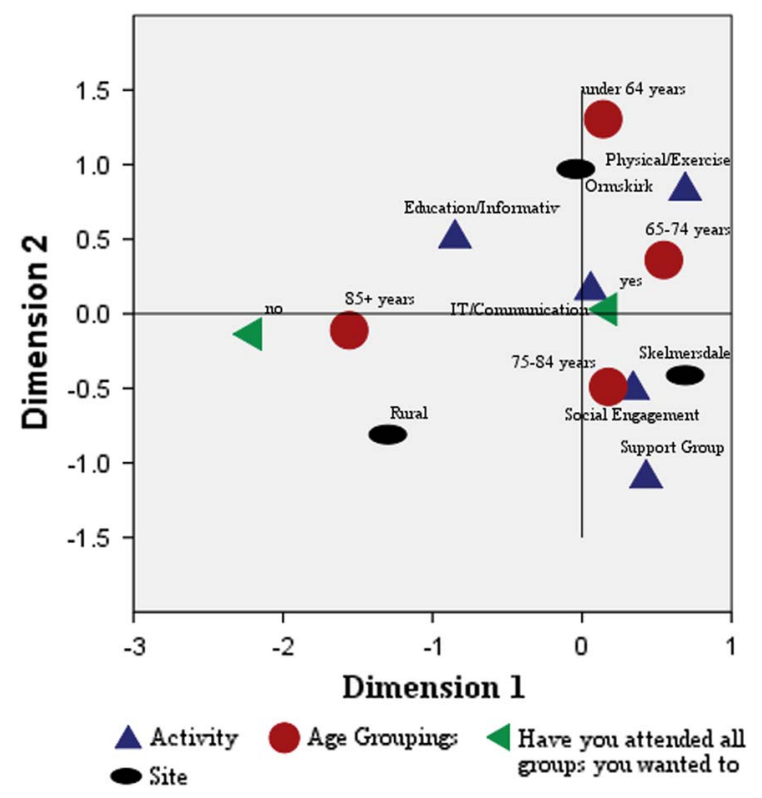

Figure 3 Segmentation of survey profiles - Phase 3

those variables which have the strongest relationships/correspondence with one another, separating them into four groups, as represented by the quadrants. The results are as follows for each survey phase.

For Phase 1, there was multiple correspondence between (i) the activity Education/Informative, the age groups under 65 years and $65-74$ years and the Rural site; (ii) the age group 65-74 years, the activity Physical/Exercise and the Ormskirk site; (iii) the activity Support Group, the age group 75-84 years and the Skelmersdale site; and (iv) the activities IT/Communications, Social Engagement and the age group $85+$ years.

For Phase 2, there was multiple correspondence between (i) the site Ormskirk, the activities Physical/Exercise, IT/Communications, the age group 65-74 years and 'Yes' as a recommendation to family and friends; (ii) the activities IT/ Communications, Education/Informative, the age group 75-84 years and 'Yes' as a recommendation to family and friends; (iii) the site Skelmersdale, the activity Support Group, the age group under 65 years; and (iv) the activity Social Engagement, the age group $85+$ years and the Rural site.

For Phase 3, there was multiple correspondence between (i) the activity Education/Informative and the Ormskirk site; (ii) the activities Physical/ Exercise, IT/Communications, the ages groups under 65 years and 65-74 years, and those attending all the groups they wanted to; (iii) those not attending all the groups they wanted to, the age group 85+ years and the Rural site; and (iv) the activities Social Engagement, Support Group, IT/ Education, the age group 75-84 years and the Skelmersdale site.

Tests for differences between means for common variables measured in different phases were undertaken: Questions F and P (Satisfaction with range of activities) and Questions C and I (agreement on activities well organised). For the former, the mean satisfaction was statistically lower $(P<0.05)$ when moving from Phase 1 to Phase 3 (Phase 1 mean = 4.21, Phase 3 mean $=4.02$ ), even though both means were in the same grouping (between satisfied and very satisfied). For the latter, there was no statistical difference between means of agreement $(P>0.05)$ moving from Phase 1 to Phase 2 (Phase 1 mean $=4.14$, Phase 2 mean $=4.12$ ) and both were in the same grouping (agree to strongly agree).

The profiles Gender, Site, Activity and Age Group were common to each survey. Tests for differences between means for variables measured for these common profile questions were 
Table 4 Tests for mean differences of variable measures when grouped or factored by profiles: summary of comparisons where statistical differences were found

\begin{tabular}{|c|c|c|c|}
\hline Phases & Tests & $\begin{array}{l}\text { Demographic } \\
\text { areas }\end{array}$ & Mean differences of items measured $(P<0.05)$ \\
\hline \multirow[t]{4}{*}{ Phase 1} & $t$-test & Gender & Agreement on activities being affordable (females higher agreement than male) \\
\hline & $\begin{array}{r}\text { One-way } \\
\text { ANOVA }\end{array}$ & Site & $\begin{array}{l}\text { Agreement on activities being well organised (Ormskirk higher agreement } \\
\text { than Rural) } \\
\text { Satisfaction with refreshments (Skelmersdale has higher satisfaction than } \\
\text { Rural) }\end{array}$ \\
\hline & & Activity & $\begin{array}{l}\text { Agreement on activities well organised (IT/Communications is higher agreement } \\
\text { than Support Group, Education/Informative) } \\
\text { Agreement on toilets satisfactory and clean (Social Engagement more satisfied } \\
\text { than Support Group) }\end{array}$ \\
\hline & & Age group & No statistical differences on any variables measured \\
\hline \multirow[t]{4}{*}{ Phase 2} & $t$-test & Gender & $\begin{array}{l}\text { Agreement on facilities appropriate for purpose (females have higher agreement } \\
\text { than males) } \\
\text { Agreement on getting enjoyment from the programme (females agree more } \\
\text { than males) }\end{array}$ \\
\hline & $\begin{array}{r}\text { One-way } \\
\text { ANOVA }\end{array}$ & Site & $\begin{array}{l}\text { Agreement on activities well organised (Ormskirk and Skelmersdale have higher } \\
\text { agreement than Rural) } \\
\text { Agreement on getting enjoyment out of the programme (Ormskirk and } \\
\text { Skelmersdale have higher agreement than Rural) } \\
\text { Agreement on helping health and well-being (Skelmersdale has higher } \\
\text { agreement than Rural) }\end{array}$ \\
\hline & & Activity & $\begin{array}{l}\text { Agreement on activities well organised (IT/Communications, Support Group } \\
\text { have higher agreement than Social Engagement, Education/Information) } \\
\text { Agreement on helping health and well-being (Support Group and Physical/ } \\
\text { Exercise have higher agreement than Education/Informative) } \\
\text { Agreement on helping social well-being and quality of life (IT/Communications } \\
\text { has higher agreement than Education/Informative) }\end{array}$ \\
\hline & & Age group & $\begin{array}{l}\text { Agreement on activities well organised (under } 64 \text { years has higher agreement } \\
\text { than } 85+\text { years and 'prefer not to say') } \\
\text { Agreement on facilities appropriate for purpose ( } 65-74 \text { years has higher } \\
\text { agreement than 'prefer not to say') } \\
\text { Agreement on helping health and well-being (under } 64 \text { years, } 65-74 \text { years, } \\
75-84 \text { years and 'prefer not to say' all higher agreement than } 85+\text { years) } \\
\text { Agreement on helping social well-being and quality of life (under } 64 \text { years, } \\
65-74 \text { years, } 85+\text { years agreed more than 'prefer not to say') }\end{array}$ \\
\hline \multirow[t]{4}{*}{ Phase 3} & $t$-test & Gender & No statistical differences on any variables measured \\
\hline & $\begin{array}{l}\text { One-way } \\
\text { ANOVA }\end{array}$ & Site & $\begin{array}{l}\text { Satisfaction with range of activities (Skelmersdale has higher satisfaction than } \\
\text { Ormskirk and Rural) } \\
\text { Degree of change in social well-being and quality of life } \\
\text { (Ormskirk and Skelmersdale have higher improvement than Rural) } \\
\text { Degree of change in social well-being and quality of life } \\
\text { (Ormskirk and Skelmersdale have higher improvement than Rural) } \\
\text { Agreement on eating more healthily since started group (Skelmersdale has } \\
\text { higher agreement than Ormskirk and Rural) }\end{array}$ \\
\hline & & Activity & $\begin{array}{l}\text { Agreement on eating more healthily since started group (Support Group has } \\
\text { higher agreement than Social Engagement, Physical/Exercise, } \\
\text { IT/Communications) }\end{array}$ \\
\hline & & Age group & No statistical differences on any variables measured \\
\hline
\end{tabular}

ANOVA $=$ analysis of variance

undertaken. Given the hundreds of comparisons involved, Table 4 summarises only those where a statistical difference was found $(P<0.05)$. Any comparisons not included in Table 4 can be inferred to be not statistically significant $(P>0.05)$; interestingly, there were no statistical differences observed for Age group on means for any variables measured in Phase 1 and Phase 3 surveys and 
no statistical differences observed for Gender on means for any variables measured in the Phase 3 survey.

Phase 2 demonstrated the largest number of differences between means of variables measured (particularly for age groups, activities and sites). All profiles demonstrated mean differences for ranges of Agreement measures in this phase. In the Phase 3 survey only the Site profile demonstrated difference for the satisfaction and improvement variables measured.

A series of tests were undertaken to observe if correlations existed between the variables measured for each survey phase. This allowed for possible co-relationships between those items measured to be determined. Where significant correlations existed this indicated that an increased agreement in one measure was related to an increased agreement or satisfaction in another measure.

For Phase 1, all variables were significantly positively correlated $(P<0.05)$ with the exception of Questions A, B and E, where no significant correlations were observed. The largest significant correlation ( $r=0.527)$ was for Question C versus Question D and the smallest significant correlation $(r=0.167)$ was for Question A versus Question G.

For the Phase 2 survey all variables were significantly positively correlated $(P<0.05$ and $P<0.01)$. The largest significant correlation $(r=0.423)$ was for Question J versus Question K and the smallest significant correlation $(r=0.213)$ was for Question J versus Question L. For all possible co-relationships observed here, increases in agreement for all measures were related to increases in agreement for others.

For Phase 3, all variables were significantly positively correlated $(P<0.05$ and $P<0.01)$. The largest significant correlation $(r=0.491)$ was for Question Q versus Question R and the smallest significant correlation $(r=0.144)$ was for Question N versus Question P. For all possible co-relationships observed here, increases in agreement, satisfaction and improvement for all measures were related to increases in agreement, satisfaction improvement in another measure.

\section{Costs analysis of active lives programme}

AUKL Active Lives Annual Year 2 report (2013; section 3.3) to the Big Lottery showed the total Big Lottery funding received for December 2011 to November 2012 was $£ 96206$ (including overheads), with a corresponding spend of $£ 95118$. The former was used in costs calculations, which utilised the total activity figures in Table 2. The overall average cost per session was $£ 81.09$, and the overall average cost per person was $£ 160.67$. The overall average cost per attendance was $£ 2.34$.

The total number of individuals shown in Table 2 overstates the actual number of individual people accessing the programme, because of replications. Applying the above mean figure of 3.0 activity groups attended per person suggests the number of different clients accessing the programme was 197, and the overall average cost estimate per person was $£ 482$.

\section{Discussion}

The clear strength of the overall evaluation was the nature of data collection across all three years of the programme, with multiple sampling and use of mixed methods approaches. Despite the limitation of using convenience samples, the response rates for all surveys were acceptable, and the analyses used were appropriate.

The results from all phases were overwhelmingly positive, although, inevitably, there were small numbers of negative responses for individual questions. In general, participants attended a wide range of activities, and agreed they were well organised and delivered. There was a good spread of participants across age groups, but far more women accessed activities than men. There were also differences in choice of activity between the sexes.

The results relating to access, facilities and transport concur with the focus group findings (Bell et al., 2014), and it is pertinent to recognise that these are typically identified as significant barriers to older people attending services (Greaves and Farbus, 2006; Hennessy, 2014). However, the programme was a time-limited pilot project, and therefore AUKL was constrained by existing facilities and transport services, particularly in Rural venues.

The numbers of responses for the surveys were all high, but importantly some groups did not provide responses in Phases 1 and 2, despite forms being handed out at all sites and activities. Accordingly, because it yielded responses from all activity groups at all sites, Phase 3 was arguably the most important survey for evaluating the impact of the whole programme. 


\section{Impact of programme}

Four Phase 3 questions were designed to establish the potential impact of attending activities on people's personal situations: health and well-being; social well-being and quality of life; social isolation; and healthy eating. No single causal relationship between the programme and individuals' situations can be assumed, as the latter is subject to many factors and influences, some beyond their control (eg, death of spouse). Nevertheless, it is reasonable to infer the impact of the programme was positive and contributed to people adopting healthier and more active lifestyles; all means for variables measured were positive (greater than neutral) indicating positive agreement, satisfaction and improvement, respectively, and all variables were significantly positively correlated $(P<0.05$ and $P<0.01)$. This is consistent with the WHO (2015) policy on active ageing.

The programme positively helped health and well-being, but it was notable that $38 \%$ of people gave a neutral response; which suggests a critical contribution to the maintenance of health and wellbeing. This concurred with focus groups' findings, which stressed links between physical activity, mental health and well-being (Bell et al., 2014), and is consistent with findings that older adults' health and well-being improves through physical activity (Angevaren et al., 2008; Yeom et al., 2009; Windle et al., 2010; Reimers et al., 2012; Chase, 2013; English et al., 2014), and cognitive decline can decrease by increasing older adults' leisure and physical activities (Angevaren et al., 2008; Stern and Konno, 2009; Plooij et al., 2012). Healthy active ageing encourages good mental well-being (Sprange et al., 2013) and certain activities decrease levels of depression (Pinniger et al., 2012). Notably, MCA indicated correspondence with: age group 65-74 years and Physical/Exercise activity in Phase 1; activities Physical/Exercise, IT/ Communications, and the age group 65-74 years for Phase 2; and activities Physical/Exercise, IT/ Communications, and age groups under 65 years and 65-74 years for Phase 3. This suggests that the two activities arguably most relevant to physical and mental health corresponded with participants aged under 75 years.

Similarly, there was (strong) agreement that the programme helped social well-being and quality of life, and helped reduce social isolation, which was consistent with the emphasis placed on making and maintaining new friendships and avoiding loneliness by the focus groups (Bell et al., 2014). Therefore, the programme addresses the growing concern of social isolation and loneliness (Findlay, 2003; Clough et al.,2007) where the impact of the latter on health can be profound, increasing the risk of premature death (McNamee, 2014). Hunter (2012) suggests that older adults with solid social networks can expect a $50 \%$ boost to longevity. MCA showed correspondence with Social Engagement and the $85+$ years age group in Phases 1 and 2, and the 75-84 years age group in Phase 3. This suggests that the activity most relevant to social well-being corresponded with the oldest participants.

Healthy eating is emphasised nationally for all age groups, let alone older people [eg, eating five portions of fruit and vegetables a day (NHS Choices, 2015)] and is politically sensitive because of increasing use of food banks (Loopstra et al., 2015). Generally, AUKL luncheon clubs are always popular and well attended. However, the related survey responses gave the lowest mean value of all questions in all three surveys (3.65), which was largely due to nearly $40 \%$ of respondents giving a neutral response to the question. After discussion, AUKL staff and the evaluation team inferred that this is the issue where the programme was likely to have had least impact because most people's meals will be provided by themselves at home. The socioeconomic status of the programme participants was not known, or specifically canvassed, as part of the evaluation; although it was assumed the programme would generally cater for those less well-off. Therefore, it was not known if some participants experienced financial difficulties which impacted on their eating habits. Responses showed site and activity-specific differences for Question O: Skelmersdale had higher agreement than Ormskirk and Rural; and Support Group had higher agreement than Social Engagement, Physical/Exercise and IT/Communications.

\section{Costs analysis of active lives programme}

It is important to emphasise the interconnectivity of the benefits yielded by the positive impacts of the programme. These were stressed by the focus groups: healthy activity and improved social engagement lead to improved memory and mental health, and less social isolation (Bell et al., 2014). That the active lives programme positively addressed all of these in combination was a major success. 
That average cost of each session, at $£ 81.09$, represents good value for money, and could be affordable for sponsors in times of constraint for public finances. The full year cost per person is either $£ 160.67$ or $£ 482$, depending upon allowance for replicated attendances. The former is comparable with the full new state pension of $£ 155.65 /$ week (April 2016) (Department of Work and Pensions, 2016). The latter can equally be considered good value for the benefits accrued when the wider aspects and costs are considered, acknowledging that different activities will impact differently (although not exclusively) on participants' health and well-being: Physical/Exercise should reduce risk of coronary artery disease and other chronic diseases, including type II diabetes, osteoporosis, obesity, depression, and cancer of the breast and colon (American Heart Association, 2003), and also stroke prevention (Howard and McDonnell, 2015); Education/Informative and IT/Communications serve to maintain mental exercise and alertness; and Social Engagement supports continued social and friendship networks.

Such prevention directly addresses some of the biggest cost areas for the NHS: falls, strokes, heart disease, obesity and dementia. It follows that active lives programmes address a wide range of the priority health and social issues which make very large demands on the NHS and the public purse. It was impossible to establish whether the programme saved more money than it cost, because there is no way of calculating how many participants would have broken their hip, had a stroke or a heart attack if they had not attended its activities. Nevertheless, given the evidence and the limited funding required, it was inferred that active lives programmes represent excellent value, based on the financial model applied.

\section{Limitations}

All surveys and collected data have limitations which need to be borne in mind when considering the results. This research was reliant on AUKL for activities data without independent verification on its reliability, validity and accuracy; which was acceptable. The data used for the costs analysis covered the most recent year available, although the exact period was not specified. Some queries were raised with AUKL staff about certain attendance numbers, but they gave assurance of their accuracy.
No data were available on numbers of people that 'dropped out' from the programme. Anecdotally, AUKL thought such numbers were small.

The 'number of individuals' was taken to be the number registered for a given activity (for the year in question). This was a mix of 'new' attendees and those attending throughout the programme, however, (in)frequently. The nature of the activity was an influence: some (eg, education courses) were for set time periods, whereas others (eg, lunch clubs) were ongoing. People attending multiple activities counted against each and every activity and site attended; and such people could complete surveys for each activity and site combination attended. This was perfectly acceptable because responses could vary for different combinations. Survey anonymity meant calculating numbers of multiple responses was not possible. To gauge the actual number of individuals participating in the overall programme, responses to the question 'How many different activity groups have you attended since 2012?' in the final survey were used to calculate the average number of different activities each client attended. This figure was then divided into the total aggregate number of individuals attending the individual activities.

It was agreed from the outset that questionnaires must be simple and anonymous, so as to maximise the number and ensure the quality of responses, given the age group involved (see the 'Reliability and validity' section). Accordingly, it was not possible to compare individuals across the phases, making any matched pairs analyses impractical. Consequently, there was reliance on self-reported changes in individual status, for the small number of related questions (see Table 3 ); any external measurement against set criteria was neither feasible nor appropriate. It should be noted that anyone participating in all survey phases may have moved from one age group to another during the overall 21-months involved; but these should be comparatively few given the 10-year age categories used.

Despite AUKL's best endeavours some groups did not provide data: six groups in Phase 1 (Ormskirk Education/Informative and Support Group; Rural IT/Communications and Physical/ Exercise; and Skelmersdale Education/Informative and IT/Communications) and four groups in Phase 2 (Rural IT/Communications, Physical/ Exercise and Support Group; Skelmersdale Education/Informative). 


\section{Summary of findings and recommendations}

The research has demonstrated that: it is possible to organise a range of health promoting activities for older people of varying ages in different urban and rural settings that will attract substantial numbers of people; respondents perceived that the activities were beneficial to their health and well-being; (in the last two surveys) activities in rural areas, which were most relevant for the hard-to-reach, showed greatest proportional usage by the very oldest; and, the costs of activities were low.

Building upon, and to a degree extrapolating from these findings and the qualitative evaluation (Bell et al., 2014), in its full report to AUKL the evaluation team made some specific recommendations. These include: such programmes involve low-cost activities yielding many benefits, and should be made more widely available; and, any future programmes should consider how to be more attractive and relevant to men, and improve access to transport.

\section{Conclusions}

The active lives programme and groups offered a wide range of flexible and local activities that provided benefits for older people in terms of health and well-being, social well-being and quality of life, and reducing social isolation. There is interconnectivity between these benefits, which the programme can deliver in an affordable and flexible manner, based on the funding model applied. Such programmes should be made more widely available.

\section{Acknowledgements}

The authors would like to acknowledge the contributions of Pauline Barraclough and Victoria Frost of Age UK Lancashire.

\section{References}

Age UK 2015: Our history. Retrieved 15 July 2015 from http:// www.ageuk.org.uk/about-us/who-we-are/our-history/.

Age UK Lancashire (AUKL) 2013: Active Li ves Annual Year 2 report; submission to Big Lottery, which was a requirement of its grant conditions.

American Heart Association 2003: Scientific statement: exercise and physical activity in the prevention and treatment of atherosclerotic cardiovascular disease. Circulation 107, 3109-116.
Angevaren, M., Aufdemkampe, G., Verhaar, H.J.J., Aleman, A. and Vanhess, L. 2008: Physical activity and enhanced fitness to improve cognitive function in older people without known cognitive impairment. Cochrane Library Cochrane Database of Systematic Reviews doi: 10.1002/14651858.CD005381.pub3, CD005381.

Bell, A., Gandy, R., Barraclough, P. and Roe, B. 2014: Benefits and impact of active lives groups for older people living in the community. Oral presentation at British Society of Gerontology Annual Conference, Southampton, 1-3 September.

Big Lottery 2015: About Us. Retrieved 15 July 2015 from https://www.biglotteryfund.org.uk/about-big.

Brown, J., Bowling, A. and Flynn, T. 2004: Models of quality of life: a taxonomy, overview and systematic review of the literature. European Forum on Population Ageing Research, London: World Health Organisation.

Chase, J.A. 2013: Physical activity interventions among older adults: a literature review. Research and Theory for Nursing Practice 27, 53-80.

Clough, R., Manthorpe, J., Green, B., Fox, D., Raymond, G., Wilson, P., Raymond, V., Sumner, K., Bright, L. and Hay, J. 2007: The support older people want and the services they need. York: Joseph Rowntree Foundation.

Department of Work and Pensions 2016: The new state pension. Retrieved 7 January 2016 from https://www.gov. uk/new-state-pension/overview.

English, C., Manns, P.J., Tucak, C. and Bernhardt, J. 2014: Physical activity and sedentary behaviours in people with stroke living in the community: a systematic review. Physical Therapy 94, 185-96.

Findlay, R.A. 2003: Interventions to reduce social isolation amongst older people: where is the evidence. Ageing and Society 23, 647-58.

Flynn, B., Schroeder, R. and Sakakibara, S. 1994: A framework for quality management research and an associated measurement instrument. Journal of Operations Management 11, 339-66.

Greaves, C.J. and Farbus, L. 2006: Effects of creative and social activity on the health and well-being of socially isolated older people: outcomes from a multi-method observational study. The Journal of the Royal Society for the Promotion of Health $126,134-42$.

Health and Safety Executive 2004: Successful interventions with hard to reach groups. Retrieved 7 January 2016 from http://www.hse.gov.uk/research/misc/hardtoreach.pdf.

Hennessy, C. 2014: Promoting older people's inclusion in rural communities. In Age UK, editor, Improving Later Life. Services for Older People - What Works. London: Age UK, pp. $48-50$.

Howard, V. and McDonnell, M. 2015: Physical activity in primary stroke prevention - just do it!. Stroke 46, 1735-739.

Hunter, D. 2012: Loneliness a public health issue. Perspectives in Public Health 132, 153.

Loopstra, R., Reeves, A., Taylor-Robinson, D., Barr, B., McKee, M. and Stuckler, D. 2015: Austerity, sanctions, and the rise of food banks in the UK. BMJ 350, h1775. 
McNamee, D. 2014: Loneliness increases risk of premature death in seniors, Medical News Today. Retrieved 1 November 2014 from http:www.medicalnewstoday.com/articles/272705.php.

NHS Choices 2015: 5 A DAY. Retrieved 15 July 2015 from http:// www.nhs.uk/livewell/5aday/Pages/5ADAYhome.aspx.

Pinniger, R., Brown, R.F., Thorsteinsson, E.B. and McKinley, P. 2012: Argentine tango dance compared to mindfulness mediation and a waiting-list control: a randomised trial for treating depression. Complementary Therapies in Medicine 20, 377-84.

Plooij, B., Scherder, E.J.A. and Eggermont, L.H.P. 2012: Physical inactivity in aging and dementia: a review of its relationship to pain. Journal of Clinical Nursing 21, 3002-08.

Reimers, C.D., Knapp, G. and Reimers, A.K. 2012: Does physical activity increase life expectancy? A review of the literature. Journal of Aging Research Article ID 243958, 9 pp., doi:10.1155/2012/243958.

Sourial, N., Wolfson, C., Zhu, B., Quail, J., Fletcher, J., Karunananthan, S., Bandeen-Roche, K., Béland, F. and Bergman, H. 2010: Correspondence analysis is a useful tool to uncover the relationships among categorical variables. Journal of Clinical Epidemiology 63, 638-46.

Sprange, K., Mountain, G.A., Brazier, J., Cook, S.P., Craig, C., Hind, D., Walters, S.J., Windle, G., Woods, R., Keetharuth, A.D., Chater, T. and Horner, K. 2013: Lifestyle matters for maintenance of health and wellbeing in people aged
65 years and over: study protocol for a randomised controlled trial. Trials 14, 302.

Stern, C. and Konno, R. 2009: Physical leisure activities and their role in preventing dementia: a systematic review. $J B I$ Library of Systematic Reviews 7, 260-308.

Windle, G., Hughes, D., Linck, P., Russell, I. and Woods, B. 2010: Is exercise effective in promoting mental well-being in older age? A systematic review. Aging and Mental Health 14, 652-69.

World Health Organisation (WHO) 2002: Active ageing: $a$ policy framework. World Health Organisation, Geneva, Switzerland. Retrieved 18 December 2012 from http://apps. who.int/iris/bitstream/10665/67215/1/WHO_NMH_NPH_ 02.8.pdf.

World Health Organisation (WHO) 2012: 'Ageing' health topics. World Health Organisation. Retrieved 18 December 2012 from http://www.who.int/topics/ageing/en/.

World Health Organisation (WHO) 2015: World report on ageing and health. World Health Organisation, Geneva, Switzerland. Retrieved 3 November 2015 from http://www. who.int/ageing/publications/world-report-2015/en/.

Yeom, H.A., Keller, C. and Fleury, J. 2009: Interventions for promoting mobility in community-dwelling older adults. Journal of the American Academy of Nurse Practitioners 21, 95-100. 